\title{
Article \\ Understanding the Coupling Effect between Lignin and Polybutadiene Elastomer
}

\author{
Sakrit Hait ${ }^{1,2}$, Debapriya De ${ }^{3}$, Prasenjit Ghosh ${ }^{4} \oplus^{\oplus}$, Jagannath Chanda ${ }^{4} \mathbb{D}$, Rabindra Mukhopadhyay ${ }^{4}$, \\ Saikat Dasgupta ${ }^{4}$, Aladdin Sallat ${ }^{5}{ }^{\mathbb{D}}$, Muhannad Al Aiti ${ }^{1,2}{ }^{\mathbb{D}}$, Klaus Werner Stöckelhuber ${ }^{1, * \mathbb{D}}$, \\ Sven Wießner ${ }^{1,2}\left(\mathbb{D}\right.$, Gert Heinrich ${ }^{1,2}$ (D) and Amit Das $1,6, *(\mathbb{B})$
}

1 Leibniz-Institut für Polymerforschung Dresden e.V., 01069 Dresden, Germany; hait@ipfdd.de (S.H.); Muhannad_Al_Aiti@outlook.de (M.A.A.); wiessner@ipfdd.de (S.W.); gheinrich@ipfdd.de (G.H.)

2 Faculty of Mechanical Science and Engineering, Technische Universität Dresden, 01069 Dresden, Germany

3 Chemistry Department, MCKV Institute of Engineering, Liluah, Howrah 711204, India; debapriyad2001@yahoo.com

4 Hari Shankar Singhania Elastomer and Tyre Research Institute, Plot No. 437, Hebbal Industrial Area, Mysore 570016, India; pghosh@jkmail.com (P.G.); jagannath.chanda@gmail.com (J.C.); rm@jkmail.com (R.M.); saikat.dasgupta@jkmail.com (S.D.)

5 Schill + Seilacher "Struktol" GmbH, 22113 Hamburg, Germany; asallat@struktol.de

6 Faculty of Engineering and Natural Sciences, Engineering Materials Science, Tampere University, 33014 Tampere, Finland

* Correspondence: stoeckelhuber@ipfdd.de (K.W.S.); das@ipfdd.de (A.D.); Tel.: +49-351-4658-579 (K.W.S. \& A.D.)

check for updates

Citation: Hait, S.; De, D.; Ghosh, P.; Chanda, J.; Mukhopadhyay, R.; Dasgupta, S.; Sallat, A.; Al Aiti, M.; Stöckelhuber, K.W.; Wießner, S.; et al. Understanding the Coupling Effect between Lignin and Polybutadiene Elastomer. J. Compos. Sci. 2021, 5, 154. https://doi.org/10.3390/jcs5060154

Academic Editor:

Francesco Tornabene

Received: 4 May 2021

Accepted: 4 June 2021

Published: 8 June 2021

Publisher's Note: MDPI stays neutral with regard to jurisdictional claims in published maps and institutional affiliations.

Copyright: (c) 2021 by the authors. Licensee MDPI, Basel, Switzerland. This article is an open access article distributed under the terms and conditions of the Creative Commons Attribution (CC BY) license (https:/ / creativecommons.org/licenses/by/ $4.0 /)$.

\begin{abstract}
From an environmental and economic viewpoint, it is a win-win strategy to use materials obtained from renewable resources for the production of high-performance elastomer composites. Lignin, being a renewable biomass, was employed as a functional filler material to obtain an elastomer composite with a higher degree of mechanical performance. In the presence of a suitable coupling agent, an elevated temperature was preferred for the reactive mixing of lignin with polybutadiene rubber (BR). It is quite fascinating that the mechanical performance of this composite was comparable with carbon black-filled composites. The extraordinary reinforcing behavior of lignin in the BR matrix was understood by an available model of rubber reinforcement. In rubber composite preparation, the interfacial interaction between polybutadiene rubber and lignin in the presence of a coupling agent enabled the efficient dispersion of lignin into the rubber matrix, which is responsible for the excellent mechanical properties of the rubber composites. The rubber composites thus obtained may lead to the development of a sustainable and cost-effective end product with reliable performance. This novel approach could be implemented in other type of elastomeric materials, enabling a genuine pathway toward a sustainable globe.
\end{abstract}

Keywords: waste utilization; lignin as a filler; lignin-rubber composites; physicomechanical properties; reinforcement

\section{Introduction}

In recent decades, the usage of fossil fuel became a global concern, mainly due its impact on the environment [1]. For a solution, several ways have been implemented by researchers, where the replacement of petroleum-derived products with renewable alternatives is the crucial one. Furthermore, the reusability of solid wastes obtained from several industries is also considered as a pathway toward sustainability [2]. However, it is a challenging task to reuse waste materials and convert it into a high-end product. As a result, the techniques such as incineration and landfilling have been adopted worldwide to dispose solid wastes. A pollution problem has originated from these activities that is quite threatening from an environmental aspect [3]. To address this issue, the transformation of existing waste materials into an alternative renewable material is the prime objective. 
Lignin, a major constituent of renewable biomass and a co-product of the paper and pulp-making industry, might be a potential feedstock that can overcome all the obstacles on the way toward sustainability [4]. Generally, lignin is considered as a low-cost waste material obtained from the paper and pulp-making industry, and it is mostly thrown away or sometimes used as a burning fuel. It has been reported that a huge amount $(\approx 75$ million tons per year) of lignin is produced by paper-making industries, but a very minute quantity $(\approx 2 \%)$ is utilized to develop value-added product [5]. However, recent study reveals that lignin was utilized in a wide range of conventional and smart applications. Lignin was introduced into the polymer matrix to improve the thermal stability [6] and flame retardancy [7] of the composites. On the other hand, lignin was utilized to develop shape memory polymer [8], self-healing elastomer [9], and renewable skin with programmable and switchable electrical conductivity [10]. Furthermore, lignin was used in energy storage [11] and 3D printing applications [12]. Lignin was also used as a precursor to produce high-performance carbon fibers [13]. It is also to be noted that a homogeneous dispersion of lignin into the polymer matrix is mandatory to get the desired properties. Indeed, the dispersion of lignin in a soft elastomar matrix is a challenging task, as lignin is a crosslinked biopolymer having a hyperbranched structure. A lot of recent studies ensured that a chemical modification of the lignin surface could solve the issue. In a recent study, a suitable coupling agent was used to improve the interaction of lignin with elastomer, which provides excellent mechanical properties [14]. Various methods were introduced in this regard, which include esterification of the available -OH groups on the lignin surface [15], the allylation of lignin moeity [16], development of phenolated lignin-based materials [17], and polymer grafting on the lignin surface [18].

In this study, we are mainly focusing on the reinforcing characteristics of lignin-based elastomer composites. In the field of elastomer technology, carbon black is considered to have a dominating role as a reinforcing filler material. However, carbon black is a nonrenewable material, as it is produced by the incomplete combustion of petroleum-derived product [19]. Therefore, the exploration of a suitable alternative of carbon black is of great significance. Considering this fact, in a few studies, lignin was used as an alternative filler material in various forms as functional additive [20], reinforcing biofiller [21], and nano-biochar [22].

Some of the research works also reported a hybrid filler system, where lignin was used along with carbon black [23], silica [24], and layered double hydroxides [25]. However, still, the application of lignin as a potential reinforcing filler is a matter of debate, as it was difficult to achieve a comparable reinforcing efficacy with respect to carbon black and other conventional fillers.

With this background, a new target has been set, where the replacement of reinforcing filler material such as carbon black by lignin is the main goal. In this study, a unique reactive mixing technique was developed, where the interaction of lignin with rubber matrix could be realized by using a chemical coupling agent. Furthermore, the impact of different lignin concentration, the quantification of rubber to lignin interaction by swelling and dynamic mechanical experiments, the alteration of the overall crosslinking densities, etc. are reported. Finally, this study inspects the results in the light of existing mathematical models regarding rubber-filler interaction, network density, and so on. It is interesting to mention in this context that this newly developed technique might open a new window in the field of tire technology in a sustainable way.

\section{Materials and Methods}

\subsection{Materials}

Polybutadiene rubber (Buna CB 24), having Mooney viscosity $\approx 44\left(\mathrm{ML}_{1+4}\right.$ at $100{ }^{\circ} \mathrm{C}$ ) and density $\approx 0.91 \mathrm{~g} / \mathrm{cm}^{3}$, was provided by Lanxess (Leverkusen, Germany). BioChoice Kraft lignin was collected from UPM $\left(T_{g}=153^{\circ} \mathrm{C}\right.$, content of hydroxyl group $=5.1 \mathrm{mmol} / \mathrm{g}$, $\mathrm{pH}$ in $10 \%$ solution $=12.1)$. Zinc oxide $(\approx 99.5 \%$ pure $)$ was supplied by Acros Organics. The chemical structures of the rubber and the lignin are shown in Figure 1. Stearic acid 
was purchased from Fisher Scientific. Carbon black (Corax-N330) was obtained from Orion Engineered Carbons (Köln, Germany). Silane coupling agent bis (3-triethoxysilyl propyl) tetrasulfide (TESPT) was provided by Evonik Industries AG. Sulfur $(\approx 99.5 \%$ pure) was provided by Acros Organics. N-cyclohexyl-benzothiazole-2-sulfenamide (CBS) and 1,3-diphenylguanidine (DPG) were obtained from Lanxess.<smiles>CC(C)C=CCC=CC1CC1</smiles>

(a)<smiles>COc1ccc(C(O)C(CO)Oc2ccc(C(C)(C)C)cc2OC)cc1OC</smiles>

(b)

Figure 1. Chemical structure of (a) polybutadiene rubber (BR) and (b) kraft lignin (KL).

\subsection{Fabrication of the Composites}

A multi-step compounding strategy was adopted to develop BR-lignin composites. The recipe of all the composites is given in Table 1. A detailed description of each individual step is given below.

Step 1: In this step, BR was masticated in a laboratory scale two-roll mill (Polymix 110 L, size: $203 \times 102 \mathrm{~mm}^{2}$, Servitech $\mathrm{GmbH}$, Wustermark, Germany) for $1 \mathrm{~min}$. Then, zinc oxide, stearic acid, and lignin were added one by one, and the mixing was continued for 10 min to get a homogeneous mixture. The mixing was carried out at room temperature with a friction ratio of 1:1.4.

Step 2: The obtained mix was incorporated into the chamber of an internal mixer (Haake ${ }^{\mathrm{TM}}$ Rheomix, Thermo Electron $\mathrm{GmbH}$, Karlsruhe, Germany) and run for $10 \mathrm{~min}$ at $155^{\circ} \mathrm{C}$ with a rotor speed of $50 \mathrm{rpm}$. The mixing temperature $\left(155^{\circ} \mathrm{C}\right)$ was chosen, which is above the glass transition temperature of lignin $\left(T_{g}=153^{\circ} \mathrm{C}\right)$.

Step 3: In this step, the mix obtained from step 2 was further incorporated into the internal mixer along with TESPT and mixed at $120^{\circ} \mathrm{C}$ for $10 \mathrm{~min}$ with a rotor speed of $50 \mathrm{rpm}$.

Step 4: Finally, the compound obtained from step 3 was mixed with CBS, DPG, and sulfur (curatives) in a two-roll mill at room temperature for $10 \mathrm{~min}$ with a friction ration of 1:1.4.

To study the rheometric characteristics, the mixed compounds were subjected to a moving die rheometer (Scarabaeus SIS-V50). Around $5 \mathrm{~g}$ of sample was placed into the machine, and the measurement was done at $160{ }^{\circ} \mathrm{C}$ for $1 \mathrm{~h}$ with a frequency of $1.67 \mathrm{~Hz}$.

Optimum curing time $\left(t_{90}\right)$ was obtained from the rheometric curve (torque vs. time). Utilizing this time $\left(t_{90}\right)$, the mixed compounds were cured using a hot press (Fontijne Holland, Model TP400, Delft, The Netherlands) at $160^{\circ} \mathrm{C}$ with $150 \mathrm{KN}$ force. After curing, the cured sheet $\left(\right.$ dimension $\left.=110 \times 100 \times 2 \mathrm{~mm}^{3}\right)$ was placed at ambient temperature for $24 \mathrm{~h}$ before performing any tests. 
Table 1. Mixing recipe of all rubber composites ${ }^{1}$.

\begin{tabular}{ccccc}
\hline Sample Designations & BR & Kraft Lignin (KL) & TESPT & Carbon Black (CB) \\
\hline BR gum & 100 & - & - & - \\
KL $_{30}$ TESPT $_{1.5}$ & 100 & 30 & 1.5 & - \\
KL $_{50}$ TESPT $_{2.5}$ & 100 & 50 & 2.5 & - \\
KL $_{70}$ TESPT $_{3.5}$ & 100 & 70 & 3.5 & - \\
KL $_{90}$TESPT $_{4.5}$ & 100 & 90 & 4.5 & - \\
CB $_{50}$ & 100 & - & - & 50 \\
\hline
\end{tabular}

${ }^{1}$ Each ingredient was taken in phr (parts per hundred parts of rubber). Except for the above ingredients, each composite contains $5 \mathrm{phr}$ zinc oxide, 2 phr stearic acid, $1.5 \mathrm{phr}$ CBS, $1.8 \mathrm{phr}$ DPG, and $1.5 \mathrm{phr}$ sulfur. The optimum amount of TESPT was investigated in our previous study, and it is maintained in this study accordingly. It is to be noted that the composite containing carbon black was mixed at room temperature, unlike other lignin-rubber composites.

\subsection{Characterizations}

The uniaxial tensile tests were carried out using dumbbell-shaped specimens (as per DIN S2). A universal testing machine (UTM, Zwick/Roell-Z010, Ulm, Germany) was used for the test according to DIN 53504. All the measurements were executed at ambient temperature, and a cross-head speed of $200 \mathrm{~mm} / \mathrm{min}$ was used. Information such as tensile strength, percentage elongation at break, 50\% modulus, and 100\% modulus were obtained from this measurement.

Dynamic mechanical properties of the compound were studied using a dynamic mechanical analyzer (GABO Qualimeter, Eplexor 150N, Ahlden, Germany). A rectangularshaped sample with dimensions of $32 \times 10 \times 2 \mathrm{~mm}^{3}$ was taken for this purpose. The measurement was carried out under tension mode with a varying temperature between -120 and $60{ }^{\circ} \mathrm{C}$ with a heating rate of $2 \mathrm{~K} / \mathrm{min}$ at a frequency of $10 \mathrm{~Hz}$ under $1 \%$ static and $0.2 \%$ dynamic strain. A strain sweep measurement was also performed with a dynamic mechanical analyzer (GABO Qualimeter, Eplexor 2000N) to investigate the dynamic mechanical properties with varying strain at constant temperature. A specimen with similar dimensions $\left(32 \times 10 \times 2 \mathrm{~mm}^{3}\right)$ was taken, and the test was carried out under $60 \%$ static strain at a constant frequency of $10 \mathrm{~Hz}$. A wide range of variation of dynamic strain $(0.01-30 \%)$ was given to the specimen.

Equilibrium swelling experiments were carried out to study the crosslink density of the composites. A small piece $(\approx 0.5 \mathrm{~g}$ ) of specimen was swelled in toluene for $72 \mathrm{~h}$ (ASTM D 6814-02). A fresh solvent was used within each $24 \mathrm{~h}$ interval. Then, the specimen was taken out from toluene, and using a filter paper, the excess solvent onto the surface was wiped off. After taking the weight of the specimen (considered as swollen weight), it was allowed to dry at room temperature for $24 \mathrm{~h}$. Once it achieved a constant weight, the dry weight of the specimen was taken. Then, by using the Flory-Rehner equation [26], the crosslink density, $v$, of the sample was calculated.

$$
v=-\frac{\ln \left(1-V_{r}\right)+V_{r}+\chi V_{r}^{2}}{V_{s}\left(V_{r}^{\frac{1}{3}}-0.5 V_{r}\right)}
$$

where

$$
V_{r}=\frac{\frac{\text { Weight of dry rubber }}{\text { Density of rubber }}}{\frac{\text { Weight of dry rubber }}{\text { Density of rubber }}+\frac{\text { Weight of absorbed solvent }}{\text { Density of solvent }}} .
$$

$V_{r}$ is the volume fraction of rubber in swollen mass, $\chi$ is the solvent-rubber interaction parameter and the value 0.30 [27] was taken for this study, and $V_{s}$ is the molar volume of the toluene.

The surface morphology of the specimens was investigated utilizing a scanning electron microscope (SEM; Zeiss Ultra Plus, Carl Zeiss Microscopy GmbH, Jena, Germany). 
The specimen was cut using an ultramicrotome at $-180^{\circ} \mathrm{C}$, and then sputter coating with platinum was carried out before performing the experiment.

A differential scanning calorimetry (DSC) study was done for all specimens using Q100 (TA Instruments, New Castle, DE, USA) coupled with an auto-sampler in the temperature range of $-100{ }^{\circ} \mathrm{C}$ to $+180^{\circ} \mathrm{C}$ at the scanning rate of $10 \mathrm{~K} / \mathrm{min}$ in nitrogen atmosphere.

\section{Results and Discussion}

The rheometric torque profile of different $B R$ compounds is shown in Figure $2 \mathrm{a}$, and the extent of curing or ultimate rheometric torque $\left(R_{\infty}=M_{H}-M_{L}\right)$ was represented as a bar diagram in Figure $2 \mathrm{~b}$. The values of scorch time $\left(t_{2}\right)$, optimum cure time $\left(t_{90}\right)$, maximum torque $\left(M_{H}\right)$, minimum torque $\left(M_{L}\right)$, and cure rate index (CRI) were summarized in Table 2. CRI was calculated using the following equation

$$
C R I=\frac{100}{\left(t_{90}-t_{2}\right)}
$$

It can be observed from Table 2 and Figure $2 \mathrm{~b}$ that the values of minimum torque, maximum torque, and the extent of cure were found to be gradually enhanced with the increasing concentration of lignin. This was due to the enhancement of viscosity in the presence of rigid filler particles. It was found that $30 \mathrm{phr}$ lignin in BR showed a lower ultimate rheometric torque value as compared to a gum compound without any filler. On the other hand, lignin-containing composites from 50 to $90 \mathrm{phr}$ displayed the expected trend by increasing the value of extent of cure.

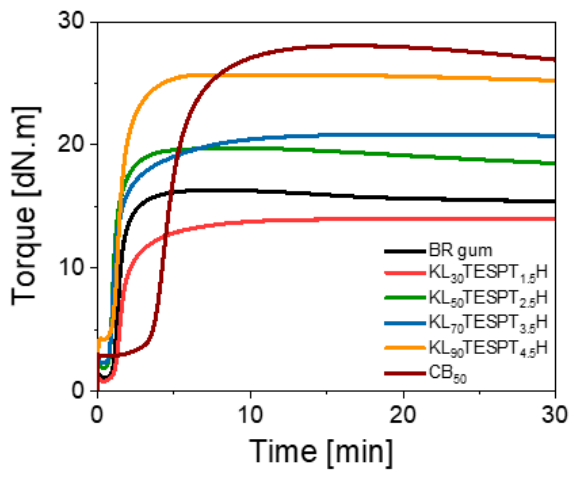

(a)

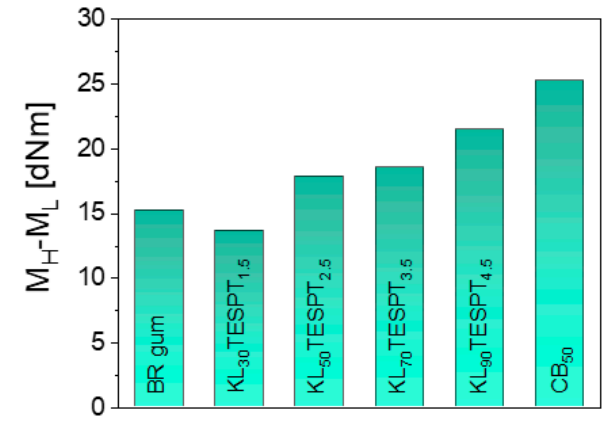

(b)

Figure 2. (a) Torque development during the vulcanization in a moving die rheometer and (b) extent of curing $\left(M_{H}-M_{L}\right)$ (represented as a bar diagram) of all the BR-lignin and BR-carbon black composites.

Now, considering the rate of vulcanization, it was evident that the scorch time $\left(t_{2}\right)$ showed a marginal increment with increasing concentration of lignin. However, in case of the composite with $90 \mathrm{phr}$ loading, a sudden enhancement of $t_{2}$ was noticed. The optimum cure time $\left(t_{90}\right)$ showed an interesting trend. The $t_{90}$ values were increasing with increasing concentration of lignin, except for the composite containing $30 \mathrm{phr}$ of lignin, which showed the highest $t_{90}$ value among the other lignin-filled composites. It is believed that sulfur vulcanization reaction is facilitated in basic medium, and here, the lignin has a $\mathrm{pH}$ value of 12.1. So, if this basic nature of lignin is considered, it could facilitate the sulfur vulcanization reaction rate. In reality, there is no such clear trend in the rheometric curves that can be explained by the $\mathrm{pH}$ factor of the filler. Since these rubber composites are multi-component systems with many chemical functional groups, a clear understanding of the vulcanization or rheometric profile is difficult at least in this stage. Nevertheless, the higher the value of $\mathrm{CRI}$, the higher the rate of vulcanization will be, and therefore, $50 \mathrm{phr}$ lignin-containing composite showed the highest value of CRI. 
The stress-strain curves and other parameters obtained from tensile stress-strain measurements of all the composites are presented in Figure 3. It was found that the mechanical properties of the composite with 30 phr loading were more or less similar to those of the gum compound. On the other hand, in the case of the composite with a higher amount of lignin-for example, $50 \mathrm{phr}$ loading, a remarkable improvement in tensile strength and elongation at break was noticed as compared to reference gum compound. As expected for the composites with further higher loading, a marginal change in tensile strength and a substantial reduction in percentage elongation at break were observed. Although TESPT improves the dispersion of lignin into the elastomer matrix, but at a higher loading of lignin, the coupling efficiency of TESPT might have reduced. Due to the strong filler-filler interaction, the materials become rigid, which inhibits the stress transmission and subsequently decreases the elongation at break.

Table 2. Curing characteristics of BR/kraft lignin/TESPT composites with various lignin content.

\begin{tabular}{cccccc}
\hline Sample Code & $\begin{array}{c}\text { Scorch Time, } \mathbf{t}_{\mathbf{2}} \\
\text { (min) }\end{array}$ & $\begin{array}{c}\text { Optimum } \\
\text { Cure Time, } \mathbf{t}_{\mathbf{9}} \\
(\mathbf{m i n})\end{array}$ & $\begin{array}{c}\text { Min. Torque, } \\
\mathbf{M}_{\mathbf{L}} \\
(\mathbf{d N m})\end{array}$ & $\begin{array}{c}\text { Max. Torque, } \\
\mathbf{M}_{\mathbf{H}} \\
(\mathbf{d N m})\end{array}$ & $\begin{array}{c}\text { Cure Rate } \\
\text { Index } \\
(\mathbf{m i n}-\mathbf{1})\end{array}$ \\
\hline BR gum & 0.86 & 2.57 & 1.10 & 16.35 & 58.47 \\
$\mathrm{KL}_{30} \mathrm{TESPT}_{1.5} \mathrm{H}$ & 0.84 & 5.76 & 0.84 & 14.48 & 20.32 \\
$\mathrm{KL}_{50} \mathrm{TESPT}_{2.5} \mathrm{H}$ & 0.83 & 2.23 & 1.93 & 19.77 & 71.42 \\
$\mathrm{KL}_{70} \mathrm{TESPT}_{3.5} \mathrm{H}$ & 0.85 & 2.95 & 2.34 & 20.87 & 47.61 \\
$\mathrm{KL}_{90} \mathrm{TESPT}_{4.5} \mathrm{H}$ & 1.03 & 4.90 & 4.20 & 25.71 & 25.83 \\
$\mathrm{CB}_{50}$ & 3.56 & 7.78 & 2.81 & 28.06 & 23.69 \\
\hline
\end{tabular}

However, the stress values at $100 \%$ elongation for both of the composites (70 phr and 90 phr) were significantly increased (Figure 3c). Subsequently, a comparative study was also done with reinforcing carbon black (CB)-filled composites. Surprisingly, it is found that the mechanical properties of the 50 phr lignin-containing composite are comparable with CB-filled composite at similar loading in terms of tensile strength, percentage elongation at break, and stress at $100 \%$ break.

To get more insight about rubber-filler interaction and filler reinforcement, the stressstrain behavior was reanalyzed by using a phenomenological equation proposed by Mooney and Rivlin [28,29], which is as follows,

$$
\frac{\sigma}{\lambda-\lambda^{-2}}=2\left(C_{1}+C_{2} \lambda^{-1}\right)
$$

where $\sigma$ is the nominal stress, $\lambda$ is the extension ratio, and $C_{1}, C_{2}$ are the Mooney-Rivlin constants.

Equation (3) can be used directly for an unfilled elastomer compound. In case of filled composites, a correction factor, namely the strain amplification factor $(x)$ was introduced, using the following equation, $x=1+2.5 \phi+7.6 \phi^{2}$, where $\phi$ is the volume fraction of filler. The extension ratio is modified by $\lambda=1+\varepsilon x$, where $\varepsilon$ is the strain. Here, pre-conditioning of the sample was done by several cyclic stress-strain operations to eliminate the Mullin's effect.

The Mooney-Rivlin plots of all the composites were obtained in Figure $3 \mathrm{~d} . C_{1}$ and $C_{2}$ values were obtained from the intercept and slope of the reduced stress $\left(\frac{\sigma}{\lambda-\lambda^{-2}}\right)$ vs. $1 / \lambda$ plot, respectively. Crosslink density $(v)$ can be calculated from $C_{1}$ by using the expression $2 C_{1}=v k T$ where $v$ is the crosslinking density, $k$ is the Boltzmann constant, and $T$ is the temperature. 


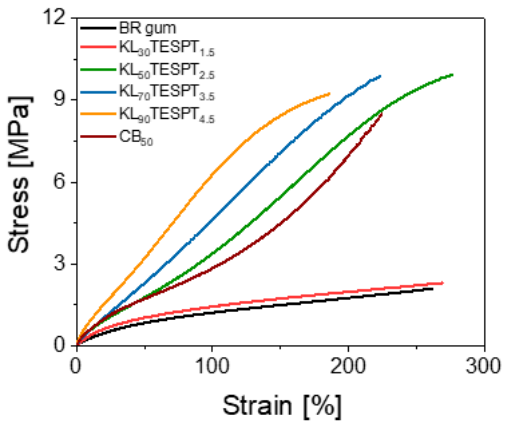

(a)

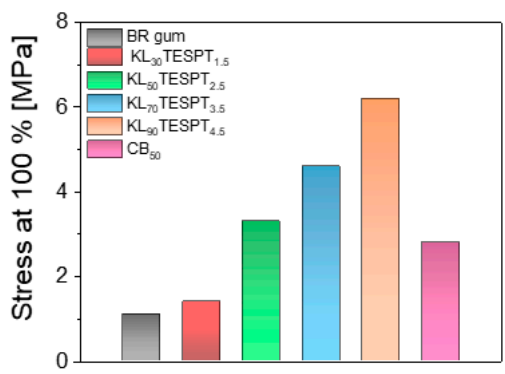

(c)

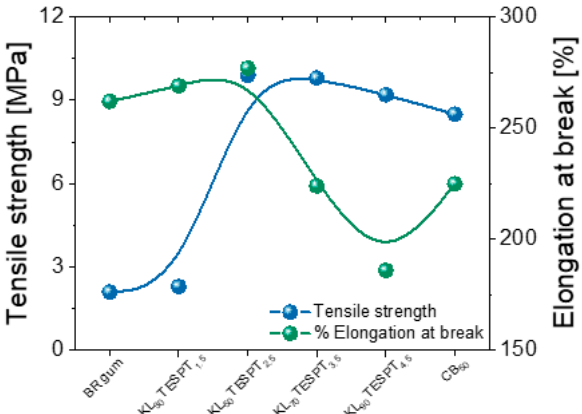

(b)

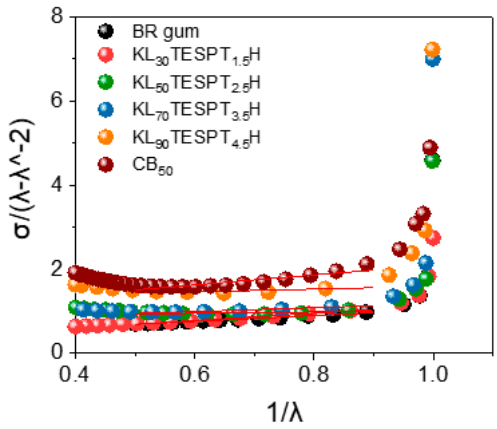

(d)

Figure 3. (a) Tensile stress-strain plot, (b) variation of tensile strength and percentage elongation at break (dot-line diagram), (c) variation of stress at 100\% break (bar diagram), (d) Mooney-Rivlin plot, of all BR-lignin and BR-CB composites.

However, the present system is a filled crosslinked rubber, so direct extraction of the crosslinking densities is not a suitable approach. However, for the comparison purpose, this approach was used to calculate apparent crosslinking densities. The values of $C_{1}, C_{2}$, and $v$ were depicted in Table 3 . The crosslink densities were found to be increased with increasing concentration of lignin.

In this context, to understand the chemical interaction of the rubber chain with lignin particles, the variation of dynamic modulus with strain amplitude will be interesting to focus. This phenomenon is also known as the "Payne effect" [30-32]. The results obtained from strain sweep experiments are depicted in Figure 4. As expected, the gum rubber sample showed almost no strain dependency in comparison with the filled sample. In case of a filled composite, a reduction in storage modulus $\left(E^{\prime}\right)$ was observed after a critical strain, which was due to the breakdown of the filler-filler network. It can be mentioned here that the magnitude or the intensity of the Payne effect is more or less similar with all filled composites irrespective of the loading amount of lignin. This might be due to the strong chemical interaction between lignin and rubber molecules in the presence of TESPT, which is very similar to the silane-silica system.

Table 3. Parameters obtained from the Mooney-Rivlin equation and calculated value of crosslink density of BR/kraft lignin/TESPT composites with various lignin content.

\begin{tabular}{cccc}
\hline Sample Code & $\boldsymbol{C}_{\mathbf{1}}$ & $\boldsymbol{C}_{\mathbf{2}}$ & Crosslink Density $\left(\mathbf{m o l} / \mathbf{c m}^{\mathbf{3}}\right)$ \\
\hline BR gum & 0.12 & 0.43 & $0.48 \times 10^{-4}$ \\
$\mathrm{KL}_{30} \mathrm{TESPT}_{1.5}$ & 0.17 & 0.35 & $0.68 \times 10^{-4}$ \\
$\mathrm{KL}_{50} \mathrm{TESPT}_{2.5}$ & 0.35 & 0.23 & $1.41 \times 10^{-4}$ \\
$\mathrm{KL}_{70} \mathrm{TESPT}_{3.5}$ & 0.42 & 0.07 & $1.69 \times 10^{-4}$ \\
$\mathrm{KL}_{90} \mathrm{TESPT}_{4.5}$ & 0.63 & 0.15 & $2.54 \times 10^{-4}$ \\
$\mathrm{CB}_{50}$ & 0.45 & 0.58 & $1.81 \times 10^{-4}$ \\
\hline
\end{tabular}


To further elucidate the rubber-lignin $r$ interactions, extension of this study has been done on the basis of agglomeration-deagglomeration phenomenon developed by Kraus [33]. According to this concept, the filler-filler network was produced by agglomeration and de-agglomeration mechanisms under dynamic strain. The equation related to this study is as follows

$$
\frac{E^{\prime}(\gamma)-E_{\infty}^{\prime}}{E_{O}^{\prime}-E_{\infty}^{\prime}}=\frac{1}{1+\left(\frac{\gamma}{\gamma_{c}}\right)^{2 m}}
$$

where $E_{0}^{\prime}$ and $E_{\infty}^{\prime}$ are the initial storage modulus and storage modulus at large strain amplitudes, respectively. $E^{\prime}(\gamma)$ is the modulus at a particular strain amplitude $\gamma, E^{\prime}(\gamma)$ becomes $E_{\infty}^{\prime}$ at larger strain; $E^{\prime}(\gamma)$ becomes $E_{0}^{\prime}$ at lower strain $\gamma_{0} ; \gamma_{c}$ is considered as critical strain, where the value of $\left(E_{0}^{\prime}-E_{\infty}^{\prime}\right)$ becomes half. It is strongly dependent on the type and character of the fillers, rubbers, and the dispersion level of filler into the rubber matrix; $m$ is a constant, which depends upon the structure of fractal agglomerate of filler materials [34]. Using the data obtained from the strain sweep experiment and Equation (4), the value of critical strain was calculated, which is shown in Figure $4 \mathrm{~b}$. It is observed that with an increasing concentration of lignin, the value of $\gamma_{c}$ was increasing. This indicates that at a relatively lower concentration of lignin, the filler-filler network was comparatively weak compared with the composites with a higher loading of lignin.

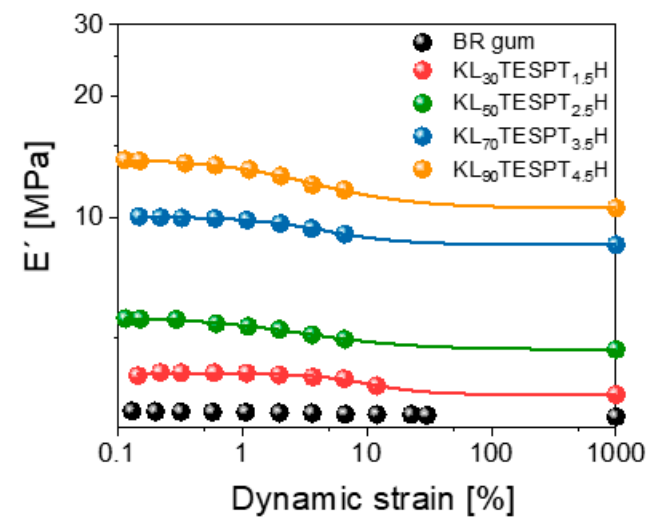

(a)

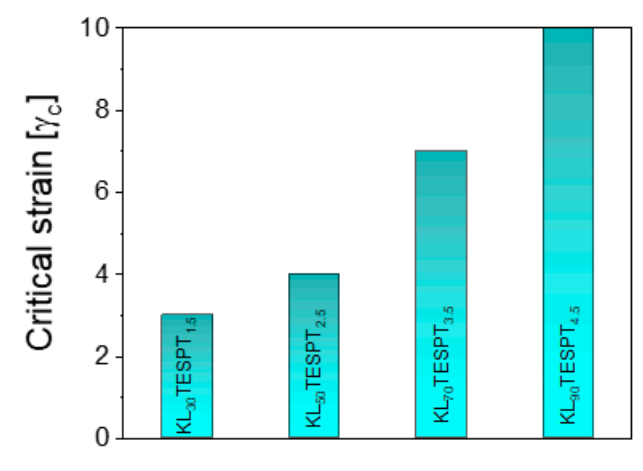

(b)

Figure 4. (a) Storage modulus as a function of dynamic strain amplitude (solid dots and solid lines represent the experimental values and the values fitted with Kraus equation, respectively) of gum BR and BR/kraft lignin (KL)/TESPT composites. (b) Variation of critical strain $\left(\gamma_{c}\right)$ of different lignin-loaded BR composites.

The equilibrium swelling experiment was further carried out to get more information regarding the influence of rubber-filler interaction on the network density of the composites. Figure 5a shows the variation of volume fraction $\left(V_{r_{f}}\right)$ of rubber in swollen gel. It was found that the value of $V_{r_{f}}$ increases with increasing lignin content. This means that the availability of free space was reduced and further solvent penetration was prevented. This observation corresponds to an improved rubber-filler interaction, which further corroborates with the previous results. The Cunneen-Russel equation [35] (Equation (5)) was utilized to assess the rubber-filler interaction.

$$
\frac{V_{r o}}{V_{r f}}=a e^{-z}+b
$$

where $V_{r_{0}}$ and $V_{r_{f}}$ are the volume fraction of the gum and filled compound respectively, $z$ is the weight fraction of the filler, and $a$ and $b$ are constants. A plot of $\left(\frac{V_{r_{0}}}{V_{r_{f}}}\right)$ versus $e^{-z}$ was represented in Figure 5b. A straight line having a positive slope (higher value of $a$ and 
lower value of $b$ indicates the improved rubber-filler interaction. In addition, the value of $\left(\frac{V_{r_{0}}}{V_{r_{f}}}\right)$ less than 1 for all the composites defines the reinforcing nature of kraft lignin.

Furthermore, the extent of reinforcement was obtained by using the Lorenz-Park equation [36]

$$
\frac{Q_{f}}{Q_{g}}=a e^{-z}+b
$$

where $Q_{f}$ and $Q_{g}$ represents the amount of solvent entrapped per unit weight of gum and filled compound, respectively. This could be calculated from the swelling data by the following expression for filled $\left(Q_{f}\right)$ and gum $\left(Q_{g}\right)$ compound. $z$ is the weight fraction of filler; $a$ and $b$ are constants. A lower value of $\left(\frac{Q_{f}}{Q_{g}}\right)$ indicates better rubber-filler interaction.

$$
Q=\frac{\text { swollen weight of the compound }}{\text { dried weight of the compound }}-1
$$

Accordingly, from Figure $5 b$, it was clearly seen that the value of $\left(\frac{Q_{f}}{Q_{g}}\right)$ was decreasing with increasing lignin loading. Most probably, the filler-filler interaction was stronger in the case of higher loaded lignin composites. The lowest value of $\left(\frac{Q_{f}}{Q_{g}}\right)$ was obtained at $90 \mathrm{phr}$ of lignin loading. This reveals that the maximum filler-filler interaction was found at the highest loading of lignin $(90 \mathrm{phr})$. The straight line obtained from the plot of $\left(\frac{Q_{f}}{Q_{g}}\right)$ against $e^{-z}$ (Figure $5 b$ ) further confirms the results obtained from strain sweep experiments.

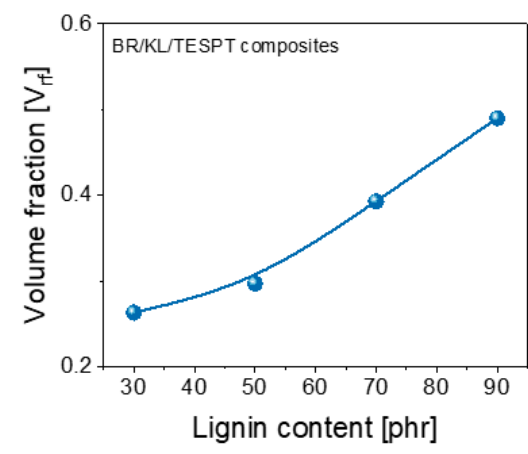

(a)

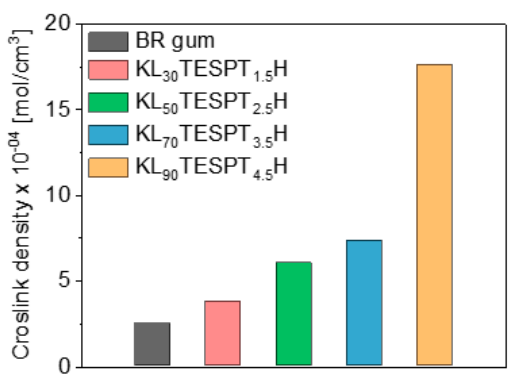

(c)

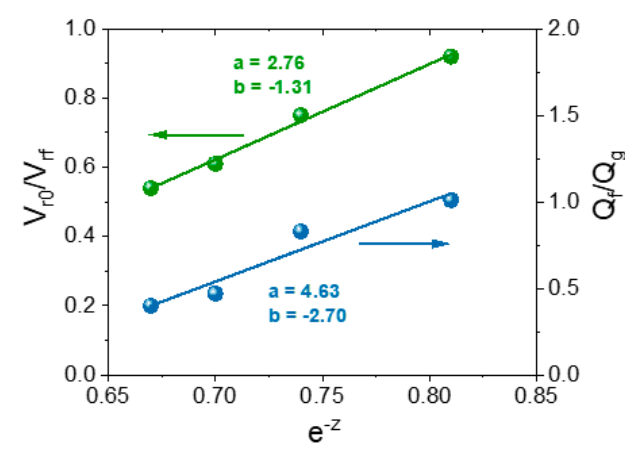

(b)

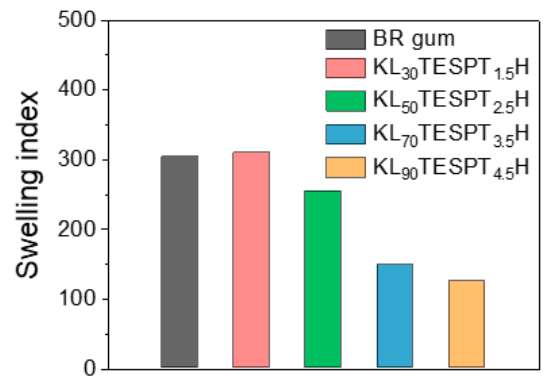

(d)

Figure 5. (a) Effect of lignin content on the volume fraction of rubber $\left(V_{r f}\right),(\mathbf{b})$ variation of $\left(\frac{V_{r o}}{V_{r f}}\right)$ with $e^{-z}$ (Cunneen-Russel plot) and variation of $\left(\frac{Q_{f}}{Q_{g}}\right)$ with $e^{-z}$ (Lorenz-Park plot), (c) crosslink density (obtained from equilibrium swelling experiment), (d) swelling index of the BR gum and $\mathrm{BR} /$ kraft lignin (KL)/TESPT composites. 
The measurement of crosslink density (shown in Figure $5 c$ as a bar diagram) further explains the reinforcing behavior of lignin in the presence of TESPT. An enhancement in crosslink density was noticed with increasing concentration of lignin and reached a maximum value at highest loading (90 phr) of lignin. This refers to the significant contribution of lignin as a filler material into the formation of network structure.

The swelling index, which was a direct measure of resistance to swelling, could be obtained by using the following expression.

$$
\text { Swelling index }(\Delta M)=\frac{\left(M_{s w}-M_{d w}\right)}{M_{i w}} * 100
$$

where $M_{s w}, M_{d w}$, and $M_{i w}$ are the swollen weight, dried weight, and initial weight of the elastomer composites, respectively. The swelling index of all the composites was shown in Figure $5 \mathrm{~d}$ as a bar chart. The swelling index signifies the availability of free space in the composite for the solvent to penetrate. If less space was available due to the formation of the dense network structure, the solvent could not be imbibed into the matrix, resulting in the value of the swelling index going down. It was shown in Figure $5 \mathrm{~d}$ that the swelling index value was going to decrease with the increasing lignin content. It means that a relatively denser network structure was formed with increasing lignin concentration, and consequently, a resistance was offered toward swelling. So, these findings were in good agreement with the results obtained from rheometric analysis and tensile experiments. Dynamic mechanical analysis (temperature sweep) was performed to study the viscoelastic properties of the elastomer composite over a wide range of temperature. The storage modulus vs. temperature curve is shown in Figure 6a for all the composites with different lignin content. The storage moduli in the rubbery plateau region were gradually increased with the lignin loading, which was expected due to the hydrodynamic reinforcement. However, an unusual behavior of storage modulus at lower temperature (after glass transition temperature) can be observed. This phenomenon can be correlated with the cold crystallization behavior of BR. At the beginning of the measurement, when the sample was heated slowly from quenched state above its glass transition temperature, the crystallites were melted, which causes a significant reduction in $E^{\prime}$ [37]. Further heating triggered growth of the crystal nucleus by the thermal activation of elastomer chains, and a rapid increment in $E^{\prime}$ was noticed. In the case of the gum rubber without any filler as well as the composites with low amounts of lignin, the effect is very strong. The effect was minimized for 50 phr lignin-containing composites, and the same disappeared at higher loading. The process of cold crystallization might be hindered at a higher concentration of lignin due to the formation of a large number of additional crosslinks in the presence of TESPT. On the other hand, a limited number of additional crosslinks were formed at lower concentration of lignin. As a consequence, a few elastomer chains were available to take part in the cold crystallization process.

In Figure $6 \mathrm{~b}$, the tan $\delta$ vs. temperature curve is shown for the BR/kraft lignin/TESPT composites with varying concentration of lignin in presence of TESPT. The reduction of $\tan \delta$ peak height and also the shift of glass transition temperature $\left(T_{g}\right)$ toward higher temperature was observed. The reduction of $\tan \delta$ peak height is associated with the improved rubber filler interaction [38]. Even at higher loading, lignin was dispersed well in the presence of TESPT. $A \approx 6{ }^{\circ} \mathrm{C}$ shift in $T_{g}$ toward higher temperature was observed for the composite with high loading of lignin ( $90 \mathrm{phr})$ compared to the gum compound. This is an indication of good rubber-filler interaction even at higher filler loading [39]. 


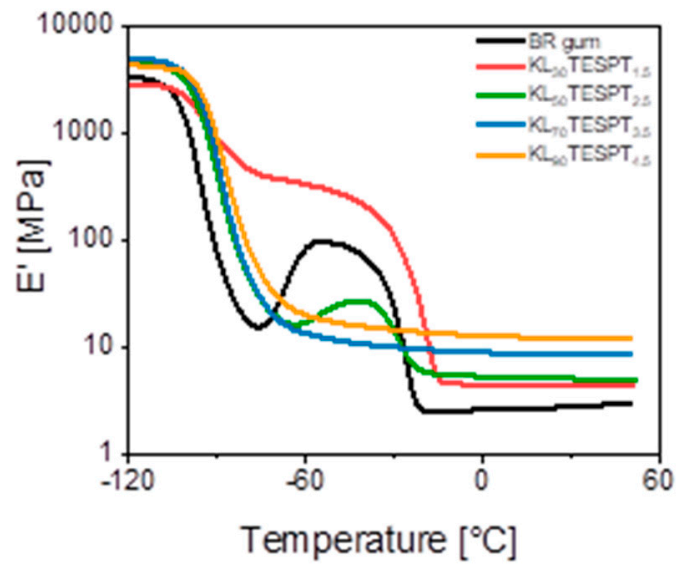

(a)

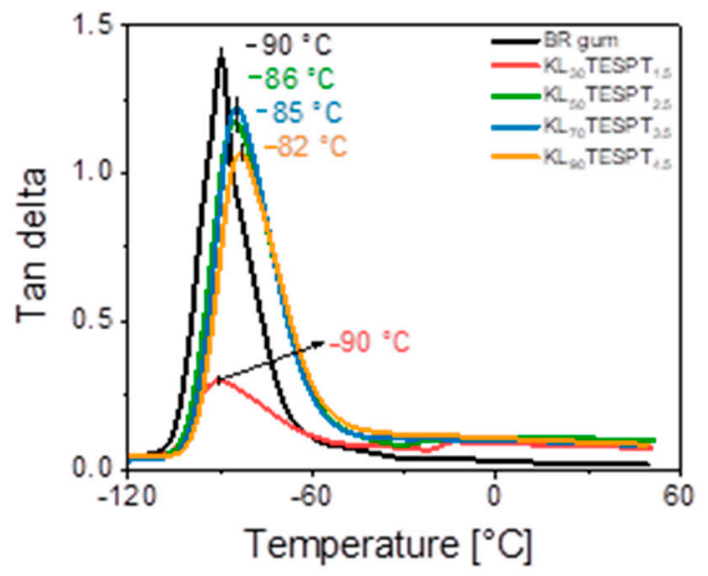

(b)

Figure 6. (a) Storage modulus as a function of temperature and (b) $\tan \delta$ as a function of temperature (obtained from dynamic mechanical analysis) for BR gum and BR/kraft lignin (KL)/TESPT composites.

A relation between the loss factor of filled composite and gum vulcanizate can be expressed as $[40,41]$

$$
\tan \delta=\frac{\tan \delta_{m}}{1+1.5 B \phi}
$$

where $B$ is phenomenological interaction parameter, and the higher value of ' $B$ ' corresponds to enhanced rubber-filler interaction, and $\phi$ is the volume fraction of the filler. $\tan \delta$ and $\tan \delta_{m}$ are the values of the peaks of filled and unfilled elastomer composites.

It can be seen from Table 4 that the value of ' $B$ ' was larger in the case of $90 \mathrm{phr}$ lignin-containing composites, which reveals a significant rubber-filler interaction at higher loading of lignin in the presence of TESPT. It was observed that the cold crystallization was more effective in case of the composites of 30 and $50 \mathrm{phr}$ loading. As a result, an unexpected trend in ' $B$ ' value (not shown in Table 4) was found. Similarly, an unusual nature in $\tan \delta$ vs. temperature curve for $30 \mathrm{phr}$ loading was also witnessed. 
Table 4. Parameters obtained from DMA analysis.

\begin{tabular}{|c|c|}
\hline Sample Designation $^{1}$ & B \\
\hline $\mathrm{KL}_{70} \mathrm{TESPT}_{3.5} \mathrm{H}$ & 0.44 \\
\hline $\mathrm{KL}_{90} \mathrm{TESPT}_{4.5} \mathrm{H}$ & 0.82 \\
\hline
\end{tabular}

${ }^{1}$ The B value estimation from the composites containing 30 and $50 \mathrm{phr}$ lignin was not carried out. The corresponding value of $\tan \delta$ was influenced by the cold crystallization behavior of the BR. This issue was already described in the discussion.

A further analysis was carried out by using scanning electron microscope (SEM) to assess the surface morphology of the composites. The information regarding the degree of lignin dispersion into the rubber matrix was also obtained. SEM micrographs of all the lignin-containing composites are given in Figure 7. The micrographs clearly demonstrate a good dispersion of lignin into the BR matrix in the presence of TESPT. A few agglomerates were found in case of lower concentration of lignin. However, in other cases, a uniform level of dispersion was witnessed. Particles were present at the submicron level, and no trace of agglomeration was observed. The higher degree of dispersion is another reason behind the mechanical reinforcement.

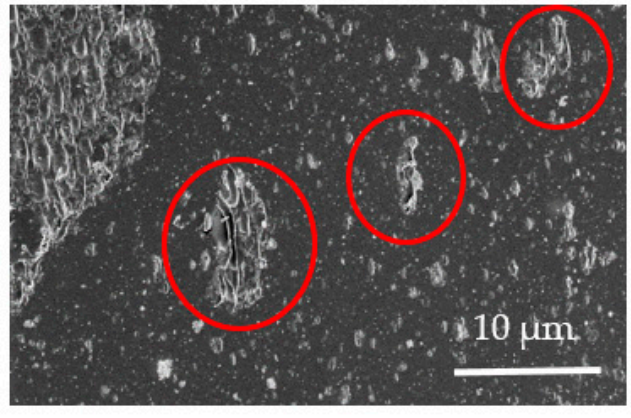

(a)

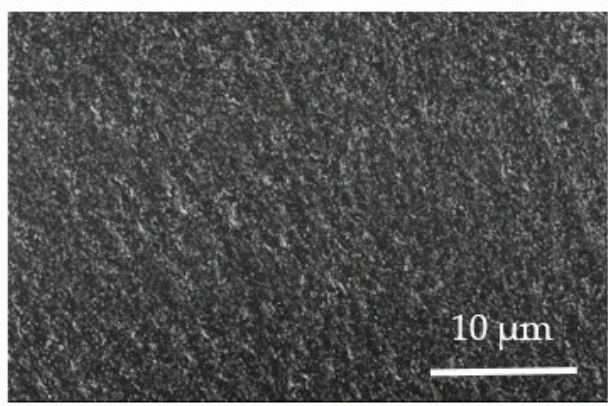

(c)

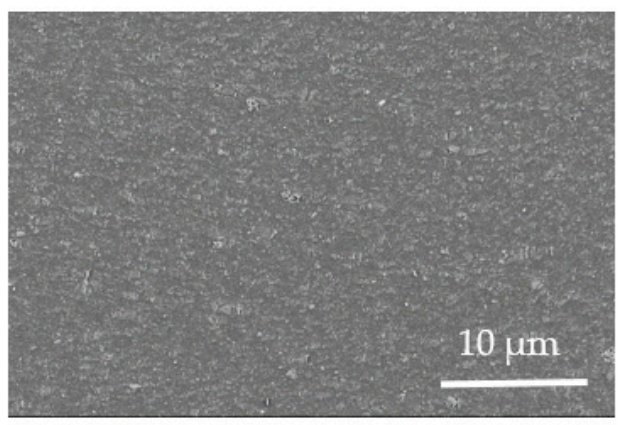

(b)

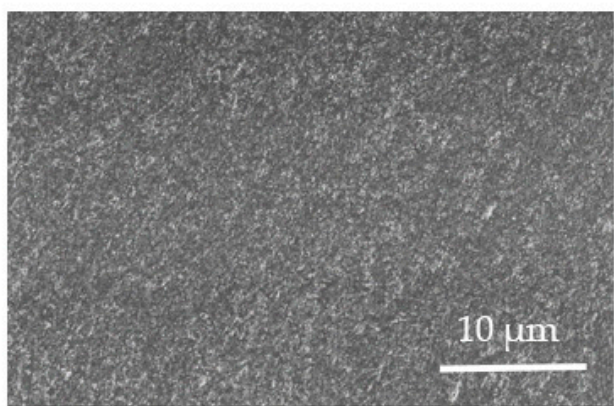

(d)

Figure 7. Scanning electron micrographs of BR-lignin composites with varying lignin concentration. The lignin concentrations are (a) 30, (b) 50, (c) 70, and (d) 90 phr. Red circles are highlighting the agglomerates present in the composite having a lower concentration of lignin.

Table 5 summarizes the parameters obtained and calculated from differential scanning calorimetric (DSC) analysis of BR/kraft lignin/TESPT composites with different concentrations of lignin. In the DSC experiment, the glass transition temperature can be detected due to changes in the heat capacity $(\Delta C p)$ of the glassy state and rubbery state. Other important information could be obtained from DSC analysis, which is the fraction of the immobilized elastomer chain $\left(x_{i m}\right)$ and can be quantified using the following expression: [42]

$$
x_{i m}=1-\frac{\Delta C p}{\Delta C p_{0}(1-w)}
$$


where $\Delta C p_{0}$ was the change in heat capacity of gum rubber compound and $w$ was the weight fraction of lignin. In Table 5, the effect of different concentrations of lignin on the heat capacity and fraction of an immobilized elastomer chain is shown. It was clear that with an increasing concentration of lignin, the $\Delta C p$ value was decreasing. The decrease of the heat capacity of a rubbery phase was only possible if the polymers were immobilized, and this would be possible if lignin particles interfere with the degrees of freedom of the elastomer chain, indicating a strong chemically bound rubber on the surface of the lignin. As a result, the extent of the immobilized rubber fraction was also increasing with lignin concentration.

Table 5. Parameters obtained from DSC analysis.

\begin{tabular}{ccc}
\hline Sample Designation & $\Delta \boldsymbol{C}_{\boldsymbol{p}}(\mathrm{J} / \mathrm{gK})$ & $\boldsymbol{X}_{\boldsymbol{i m}}$ \\
\hline $\mathrm{BR}+50 \mathrm{phr} \mathrm{KL}$ & 0.032 & 0.10 \\
$\mathrm{KL}_{30} \mathrm{TESPT}_{1.5} \mathrm{H}$ & 0.042 & 0.12 \\
$\mathrm{KL}_{50} \mathrm{TESPT}_{2.5} \mathrm{H}$ & 0.015 & 0.18 \\
$\mathrm{KL}_{70} \mathrm{TESPT}_{3.5} \mathrm{H}$ & 0.008 & 0.20 \\
$\mathrm{KL}_{90} \mathrm{TESPT}_{4.5} \mathrm{H}$ & 0.004 & 0.21 \\
\hline
\end{tabular}

\section{Conclusions}

Considering certain environmental issues, an effort was given to utilize lignin as a reinforcing filler component in polybutadiene rubber. The high temperature-driven melt mixing process enables developing strongly reinforced BR composites. A variation of the lignin loading explores the optimum loading of lignin, and excellent mechanical properties were obtained with $50 \mathrm{phr}$ lignin-containing composites, which is even better than the carbon black filler BR composites with similar loading. A comparable property was noticed with increasing concentration of lignin (70 and $90 \mathrm{phr}$ ), but the $100 \%$ modulus value showed a significant enhancement compared to the other composites. It indicates that a higher amount of lignin would have an impact on the crosslink network density. This result is in good agreement with the results obtained from equilibrium swelling experiments. Dynamical mechanical analysis provides a clear idea regarding the rubber-filler interaction. A distinct knowledge regarding the degree of dispersion was gained from scanning electron microscopic measurements. The effect of lignin particles on the crosslink network structure of the composites was also analyzed in terms of the fraction of the immobilized rubber chain, which was calculated from DSC analysis. Therefore, from this study, it is concluded that lignin could be considered as a potential reinforcing filler (obtained from renewable resources) as an alternative of existing petroleum-derived filler materials.

Author Contributions: Conceptualization, S.H.; methodology, S.H.; software, S.H.; validation, R.M.; formal analysis, S.D.; investigation, S.H.; resources, M.A.A., J.C. and A.S.; data curation, D.D.; writing—original draft preparation, S.H.; writing—review and editing, P.G., K.W.S., S.W., G.H. and A.D.; visualization, S.H.; supervision, S.W. and A.D.; project administration, S.W.; funding acquisition, A.D. All authors have read and agreed to the published version of the manuscript.

Funding: This project was partially supported by Hari Shankar Singhania Elastomer \& Tyre Research Institute (HASETRI). Part of the work was funded by DFG Research Training Group 2430, project no. 380321452.

Data Availability Statement: Not applicable.

Acknowledgments: C. Hübsch from UPM is acknowledged for providing us with the BioChoice Kraft Lignin. S. Hait thankfully acknowledges H. Scheibner for the mechanical stress-strain experiment. Authors were also thankful to S. Krause for DSC experiments. S. Hait acknowledges R. Jurk for technical help and scientific discussion.

Conflicts of Interest: The authors declare no conflict of interest. 


\section{References}

1. Nanda, S.; Dalai, A.K.; Berruti, F.; Kozinski, J.A. Biochar as an exceptional bioresource for energy, agronomy, carbon sequestration, activated carbon and specialty materials. Waste Biomass Valorization 2016, 7, 201-235. [CrossRef]

2. Silva, A.; Rosano, M.; Stocker, L.; Gorissen, L. From waste to sustainable materials management: Three case studies of the transition journey. Waste Manag. 2017, 61, 547-557. [CrossRef] [PubMed]

3. Das, O.; Sarmah, A.K.; Bhattacharyya, D. A novel approach in organic waste utilization through biochar addition in wood/polypropylene composites. Waste Manag. 2015, 38, 132-140. [CrossRef] [PubMed]

4. Ragauskas, A.J.; Beckham, G.T.; Biddy, M.J.; Chandra, R.; Chen, F.; Davis, M.F.; Davison, B.H.; Dixon, R.A.; Gilna, P.; Keller, M. Lignin valorization: Improving lignin processing in the biorefinery. Science 2014, 344, 1246843. [CrossRef]

5. Zhang, X.; Tu, M.; Paice, M.G. Routes to potential bioproducts from lignocellulosic biomass lignin and hemicelluloses. BioEnergy Res. 2011, 4, 246-257. [CrossRef]

6. Jiang, C.; He, H.; Jiang, H.; Ma, L.; Jia, D. Nano-lignin filled natural rubber composites: Preparation and characterization. Express Polym. Lett. 2013, 7, 480-493. [CrossRef]

7. Xing, W.; Yuan, H.; Yang, H.; Song, L.; Hu, Y. Functionalized lignin for halogen-free flame retardant rigid polyurethane foam: Preparation, thermal stability, fire performance and mechanical properties. J. Polym. Res. 2013, 20, 234. [CrossRef]

8. Sivasankarapillai, G.; Li, H.; McDonald, A.G. Lignin-based tripple shape memory polymers. Biomacromolecules 2015, 16, 2735-2742. [CrossRef]

9. Cui, M.; Nguyen, N.A.; Bonnesen, P.V.; Uhrig, D.; Keum, J.K.; Naskar, A.K. Rigid oligomer from lignin in designing of tough, self-healing elastomers. ACS Macro Lett. 2018, 7, 1328-1332. [CrossRef]

10. Nguyen, N.A.; Meek, K.M.; Bowland, C.C.; Barnes, S.H.; Naskar, A.K. An acrylonitrile-butadiene-lignin renewable skin with programmable and switchable electrical conductivity for stress-strain sensing application. Macromolecules 2018, 51, 115-127. [CrossRef]

11. Wei, D.; Wu, C.; Jiang, G.; Sheng, X.; Xie, Y. Lignin-assisted construction of well-defined 3D graphene aerogel/PEG form-stable phase change composites towrds efficient solar thermal energy storage. Sol. Energy Mater. Sol. Cells 2021, 224, 111013. [CrossRef]

12. Ebers, L.S.; Arya, A.; Bowland, C.; Glasser, W.; Chmely, S.; Naskar, A. 3D printing of lignin: Challenges, oppurtunities and road onward. Biopolymers 2021, e23431. [CrossRef]

13. Al Aiti, M.; Das, A.; Kanerva, M.; Järventausta, M.; Johansson, P.; Scheffler, C.; Göbel, M.; Jehnichen, D.; Brünig, H.; Wulff, L.; et al Dry-Jet Wet Spinning of Thermally Stable Lignin-Textile Grade Polyacrylonitrile Fibers Regenerated from Chloride-Based Ionic Liquids Compounds. Materials 2020, 13, 3687. [CrossRef]

14. Hait, S.; De, D.; Ghosh, A.K.; Al Aiti, M.; Ghosh, P.; Chanda, J.; Mukhopadhyay, R.; Dasgupta, S.; Wießner, S.; Heinrich, G. Treasuring Waste Lignin as Superior Reinforcing Filler in High cis-Polybutadiene Rubber: A Direct Comparative Study with Standard Reinforcing Silica and Carbon Black. J. Clean. Prod. 2021, 299, 126841. [CrossRef]

15. Hong, S.-H.; Park, J.H.; Kim, O.Y.; Hwang, S.-H. Preparation of chemically modified lignin-reinforced PLA biocomposites and their 3D printing performance. Polymers 2021, 13, 667. [CrossRef]

16. Ribca, I.; Jawerth, M.E.; Brett, C.J.; Lawoko, M.; Schwartzkopf, M.; Chumakov, A. Exploring the effects of different crosslinkers on lignin-based thermoset properties and morphologies. ACS Sustain. Chem. Eng. 2021, 9, 1692-1702. [CrossRef]

17. Zhen, X.; Li, H.; Xu, Z.; Wang, Q.; Zhu, S.; Wang, Z. Facile synthesis of lignin-based epoxy resin with excellent thermal-mechanical performance. Int. J. Biol. Macromol. 2021, 182, 276-285. [CrossRef] [PubMed]

18. Cao, Q.; Wu, Q.; Dai, L.; Shen, X.; Si, C. A well-defined lignin-based filler for tuning the mechanical properties of polymethyl methacrylate. Green Chem. 2021, 23, 2329-2335. [CrossRef]

19. Probst, N.; Donnet, J. Carbon Black, Science and Technology; Donnet, J.B., Bansal, R.C., Wang, M.J., Eds.; CRC Press: Boca Raton, FL, USA, 1993.

20. Barana, D.; Orlandi, M.; Zoia, L.; Castellani, L.; Hanel, T.; Bolck, C. Lignin based functional additives for natural rubber. ACS Sustain. Chem. Eng. 2018, 6, 11843-11852. [CrossRef]

21. Ikeda, Y.; Phakkeeree, T.; Junkong, P.; Yokohama, H.; Phinyocheep, P.; Kitano, R. Reinforcing biofiller "Lignin" for high performance green natural rubber nanocomposites. RSC Adv. 2017, 7, 5222-5231. [CrossRef]

22. Jiang, C.; Bo, J.; Xiao, X.; Zhang, S.; Wang, Z.; Yan, G. Converting waste lignin into nano-biochar as a renewable substitute of carbon black for reinforcing styrene butadiene rubber. Waste Manag. 2020, 102, 732-742. [CrossRef]

23. Bahl, K.; Miyoshi, T.; Jana, S.C. Hybrid fillers of lignin and carbon black for lowering of viscoelastic loss in rubber compounds. Polymer 2014, 55, 3825-3835. [CrossRef]

24. Strzemiecka, B.; Klapiszewski, Ł.; Jamrozik, A.; Szalaty, T.J.; Matykiewicz, D.; Sterzyński, T.; Voelkel, A.; Jesionowski, T. Physicochemical characterization of functional lignin-silica hybrid fillers for potential application in abrasive tools. Materials 2016, 9, 517. [CrossRef]

25. Xiao, S.; Feng, J.; Zhu, J.; Wang, X.; Yi, C.; Su, S. Preparation and characterization of lignin-layered double hydroxide/styrenebutadiene rubber composites. J. Appl. Polym. Sci. 2013, 130, 1308-1312. [CrossRef]

26. Flory, P.J.; Rehner, J., Jr. Statistical mechanics of cross-linked polymer networks I. Rubberlike elasticity. J. Chem. Phys. 1943, 11, 512-520. [CrossRef]

27. Marzocca, A.; Garraza, A.R.; Mansilla, M. Evaluation of the polymer-solvent interaction parameter $\chi$ for the system cured polybutadiene rubber and toluene. Polym. Test. 2010, 29, 119-126. [CrossRef] 
28. Mooney, M. A theory of large elastic deformation. J. Appl. Phys. 1940, 11, 582-592. [CrossRef]

29. Rivlin, R.S.; Saunders, D. Large elastic deformations of isotropic materials VII. Experiments on the deformation of rubber. Philos. Trans. R. Soc. Lond. Ser. 1951, 243, 251-288.

30. Payne, A.; Whittaker, R. Low strain dynamic properties of filled rubbers. Rubber Chem. Technol. 1971, 44, 440-478. [CrossRef]

31. Payne, A.R. The dynamic properties of carbon black-loaded natural rubber vulcanizates. Part I. J. Appl. Polym. Sci. 1962, 6, 57-63. [CrossRef]

32. Payne, A.R. The dynamic properties of carbon black loaded natural rubber vulcanizates. Part II. J. Appl. Polym. Sci. 1962, 6, 368-372. [CrossRef]

33. Kraus, G. Reinforcement of elastomers by carbon black. Angew. Makromol. Chem. 1977, 60, 215-248. [CrossRef]

34. Bhagavatheswaran, E.S.; Parsekar, M.; Das, A.; Le, H.H.; Wiessner, S.; Stöckelhuber, K.W.; Schmaucks, G.; Heinrich, G. Construction of an interconnected nanostructured carbon black network: Development of highly stretchable and robust elastomeric conductors. J. Phys. Chem. C 2015, 119, 21723-21731. [CrossRef]

35. Cunneen, J.; Russell, R. Occurrence and prevention of changes in the chemical structure of natural rubber tire tread vulcanizates during service. Rubber Chem. Technol. 1970, 43, 1215-1224. [CrossRef]

36. Parks, C.; Lorenz, O. Crosslinking efficiency in the reaction of dicumyl peroxide with dimethyloctadiene. J. Polym. Sci. 1961, 50, 287-298. [CrossRef]

37. McKenna, G.B. Looking at the glass transition: Challenges of extreme time scales and other interesting problems. Rubber Chem. Technol. 2020, 93, 79-120. [CrossRef]

38. Narongthong, J.; Wießner, S.; Hait, S.; Sirsinha, C.; Stöckelhuber, K.W. Strain-rate independent small-strain-sensor: Enhanced responsiveness of carbon black filled conductive rubber composites at slow deformation by using an ionic liquid. Compos. Sci. Technol. 2020, 188, 107972. [CrossRef]

39. Basu, D.; Das, A.; Wang, D.Y.; George, J.J.; Stöckelhuber, K.W.; Boldt, R.; Leuteritz, A.; Heinrich, G. Fire-safe and environmentally friendly nanocomposites based on layered double hydroxides and ethylene propylene diene elastomer. RSC Adv. 2015, 6, 26425-26436. [CrossRef]

40. Ziegel, K.; Romanov, A. Modulus reinforcement in elastomer composites. I. Inorganic fillers. J. Appl. Polym. Sci. 1973, 17, 1119-1131. [CrossRef]

41. Dutra, R.C.; Soares, B.G.; Campos, E.A.; De Melo, J.D.; Silva, J.L. Composite materials constituted by a modified polypropylene fiber and epoxy resin. J. Appl. Polym. Sci. 1999, 73, 69-73. [CrossRef]

42. Li, Y.; Ishida, H. A study of morphology and intercalation kinetics of polystyrene-organoclay nanocomposites. Macromolecules 2005, 38, 6513-6519. [CrossRef] 